Often excluded from discussion of care regarding a parent for whom they were main carer or involved in caring. Not always given the opportunity to talk about the impact of supporting and living with a dying parent or relative.

Children and young people shared heartfelt personal experiences which supported our concerns regarding the following:

Young carers described the challenges accessing support, spoke candidly about the restrictions and barriers they faced, and talked about the need to have some time away, to work out their feelings and wanting a safe space.

What we did A young persons' advisory group was formed and led on the development and design of 'Our Space'.

Collaboration with the local community to fundraise for the build of 'Our Space' in the hospice's gardens.

Opening of a dedicated resource for children and young people within an adult hospice ensuring their voices, views hopes and aspirations are at the heart of the care and support we provide.

Development of peer support groups.

\section{P-197 EXPLORING THE SUCCESS OF PALLIATIVE CARE PROVISION IN UGANDA}

Maya Connolly. Wirral University Teaching Hospital, Merseyside, UK

\subsection{6/bmjspcare-2019-HUKNC.219}

Background The majority of palliative care needs (78\%) are in low to middle-income countries; despite this, palliative care provision remains poor. Over the past 20 years, developing palliative services has increasingly become a priority for international organisations. Uganda has developed the most effective palliative care service in Sub-Saharan Africa. Globally, its palliative care services have been classed (alongside 20 other countries) as one of the most advanced palliative care services, in which 'hospice-palliative care services are at a stage of advanced integration into mainstream service provision'.

Aims Explore the potential factors which aided the development of palliative care services in Uganda and consider the lessons we can learn from this successful case study.

Methods Multi-source literature review.

Results Hospice Africa Uganda (HAU) was established in Uganda (1993) by a UK based palliative care physician. The hospice aimed to create a model of palliative care which was affordable, culturally acceptable and could be adapted to other countries in Africa.

Key factors this poster will explore, include:

- Ensured prescribing and giving opiates was not illegal and that there was sufficient supply at a reasonable cost to the service - this remains a barrier to the delivery of palliative care internationally;

- Strong research focus - service evaluation and improvement;

- Healthcare model - Integrated Community Home-Based Care which trained community volunteers supported and supervised by clinicians - care is delivered at a combination of hospitals, hospices and in the community;

- Integration of palliative care education into undergraduate and postgraduate programmes - this has led to a shift in attitudes towards palliative care and in the understanding of the importance of respect and individualised care;

- The social and political climate - Uganda was rebuilding itself with significant international financial support; the civil war had come to an end seven years before.

\section{P-198 NURSE-LED CARE FOR NON-COMPLEX DYING: A COLLABORATION BETWEEN HOSPICE AND ACUTE HOSPITAL}

Carly Wills, Sarah Grove. Arthur Rank Hospice Charity, Cambridge, UK

10.1136/bmjspcare-2019-HUKNC.220

The acute trust has severe bed capacity issues. Patients were dying on busy, acute hospital wards but often did not meet the criteria for admission to a specialist hospice bed due to lack of specialist palliative care needs. We had a new purposebuilt hospice with extra non-commissioned beds that we knew could benefit our community.

Our intention was to allow people to have a dignified death in more suitable surroundings. This resulted in us launching the nurse-led bed initiative; skilled nurses who are trained in caring for people at end of life run the beds with minimal medical input.

The service in its first year has seen over 250 patients, saving the acute trust over 2600 bed days. The average length of stay for patients is 10 days. The shortest stay was one hour; the longest 87 days. The feedback from patients and families shows it has been an overwhelming success. Nurses feel empowered to make decisions regarding patient care and have been working in partnership with teams at Cambridge University Hospital to champion the pilot and communicate its success. Patients are feeling more in control by having an alternative to staying in hospital. Families are not limited by visiting hours or other restrictions and can stay overnight. All rooms have access to outside and pets can visit.

The next step is to make it a seven day a week service as, due to current resources, it runs Monday to Friday. This may increase occupancy in the beds, thus meaning that an even greater number of patients are likely to have a better experience at the end of life.

'It's just everything it should be; peaceful, light, airy, clean and staff that are attentive and know what's going on. I press the buzzer and they are there.' Patient's relative.

\section{P-199 UK HOSPICE HEALTH LINKS WITH INTERNATIONAL PALLIATIVE CARE PROVIDERS: BENEFITS AND CHALLENGES}

Jan Eversfield. Royal Free Hospital NHS Trust, London, UK

10.1136/bmjspcare-2019-HUKNC.221

United Kingdom (UK) hospices historically have a history of health links or partnerships with resource-constrained countries to share learning through 'twinning' programmes, the donation of equipment or supplies. With no central database of these links, this study sought to map current, active health links with UK hospices.

Every UK hospice was contacted and there was a $22 \%$ response rate. The author conducted semi-structured telephone interviews with all of the respondents to understand their active health link, the benefits and challenges of the health links and interviews offered advice to UK hospices looking to develop health links in the future. The majority of the health links were educational in focus. Ten hospices had active health links with resource-constrained countries, while a further five had developed international health links with countries not 
classified as resource-constrained but identified as a positive mutual need. Results were divided into these groups accordingly for comparison.

All of the health links had been initiated by an individual with a passion for the work and some respondents asked for anonymity in their interviews. Overall, the benefits of these health links have been shown to be of mutual learning and respect and were personally transformative where positive professional relationships developed. Participants were clear they would like a national coordination system for resources, sharing information and to promote engagement in this work to avoid 'reinventing the wheel'. There was concern about longer term sustainability of the work and concern for international equity of care for patients.

Participants had clear advice for those hospices wishing to develop active health links in the future. The key suggestions were for research prior to establishing the health link, clear aims and objectives and making the right connections for the health link.

'Do not leave those suffering behind' (Worldwide Hospice Palliative Care Association, 2014)

\section{\begin{tabular}{|l|l}
\hline P-200 ST MARY'S LIVING WELL CENTRE - WORKING \\
\hline
\end{tabular} COLLABORATIVELY TO MAKE A DIFFERENCE EARLIER}

Val Stangoe. St Mary's Hospice, Ulverston, UK

\subsection{6/bmispcare-2019-HUKNC.222}

Barrow-in-Furness residents die 10 years earlier than local peers, $61 \%$ over 65 live with disability and the town rates high in fiscal and health deprivation. Despite the town's level of need, in 2018 only half the expected GSF 1\% used hospice services. This project is based on the belief that we need to reach more people but cannot allow this to mean ever spiralling costs. We set a target of 70 more people for each of five years.

Our work with partners lets us engage earlier with more people, particularly those who may not previously have considered hospice services as being for them. A side benefit of working with partners is the development of smoother referral pathways. Working through others' resources keeps costs sustainable and relatively constant.

The clinical service is delivered from a building shared with our furniture warehouse to keep costs low and increase public visibility. We actively sought centre partners who were already working with our target client groups and also approached those holding community wellbeing assets (such as art, craft and exercise) offering opportunities to meet their own targets by providing no cost services to our centre users.

From November 2018 to May 2019 monthly footfall rose to 250 , through engagement with those living with advancing lung disease, dementia, neurological conditions and stroke. Classes provided by Adult Education and the local leisure centre which start in the Summer should increase this to nearer 330. Our local ICCs are part of our Steering Group and now planning to include cardiac conditions.

As our hospice is continually pressed by limited income, increased aging and the need to reach hard to reach groups, we are finding this centre has addressed those issues at minimal cost whilst enhancing the profile we have with local funders and supporters. TO END OF LIFE CARE

Debbie Sevant. Farleigh Hospice, Chelmsford, UK

\subsection{6/bmjspcare-2019-HUKNC.223}

Context A system wide review of end of life care services identified a number of gaps in service provision. A Hospice Enhanced End of Life Care project was commissioned to;

- Extend availability of hospice advice line from 8 to 8,7 days a week.

- An enhanced hospice at home $(\mathrm{H} @ \mathrm{H})$ service including:

- An increase in availability of $\mathrm{H} @ \mathrm{H}$ within the community/ care homes from 8 to 8,7 days a week;

- Introduction of community rapid response service 8 to 8,7 days a week;

- Introduction of a specialist palliative care In-Reach Service to coordinate rapid end of life care discharges from hospital.

Key achievements

Service user feedback: 'Without your help and support my husband would have died in hospital. You provided and arranged rapid discharge so my husband could come home. We are very grateful for everything you have done.'

Professional's feedback-'Very friendly, helpful and quick to respond. Had very good feedback from patients and relatives. Have really helped make getting patients where they want to be so much easier and quicker which is greatly appreciated.'

- Referrals increased by $24.09 \%$ (target 9\%);

- Calls to the hospice advice line increased by $23 \%$ (target $17 \%$ );

- Preferred place of death achieved $100 \%$ to $88 \%$ (the target was $88 \%$ and in some months the target was over achieved and met up to $100 \%$ );

- Increase in hospital ward referrals, improving time taken from referral to assessment by less than 24hours in most cases;

- Average 25 referrals monthly;

- The average $24-$ hour response time increased by $23 \%$.

Key strategic success

- Demonstrated impact of a whole systems approach to end of life care;

- Working in partnership with local hospital, community providers and Clinical Commissioning Group;

- Raised the profile of end of life care within the acute setting;

- Relationship building between partners creating a 'bridge' engendering a genuine 'can do attitude';

- Fast track provision appropriately targeted with a regular review of the patient's needs to optimise the use of resources;

- Allows a more flexible delivery of individualised care according to changing needs for people.

\section{P-202 IT'S ALL ABOUT YOU . . A PERSON CENTRED MDT DEVELOPMENT PROJECT}

Sarah Fradsham, Dominic Bray, Ruth Pryce, Colette Parfitt, Emma Kirk, Clare Carr, Lorraine Howard, Anne Howard. Marie Curie Hospice, Liverpool, UK

\subsection{6/bmjspcare-2019-HUKNC.224}

Background Our specialist palliative care unit is currently undertaking a project to improve the 'person-centredness' of the care it provides. It was recognised that the MDT (multidisciplinary team) meeting for our 26 inpatient beds could be 